\title{
The Photoneuroendocrine Control of Seasonal Breeding in the Ewe
}

\author{
Sandra J. Legan and Sarah S. Winans \\ Department of Physiology and Biophysics, University of Kentucky, Lexington, Kentucky 40536 and \\ Department of Anatomy, The University of Michigan, Ann Arbor, Michigan 48109
}

Accepted March 5, 1981

\begin{abstract}
The major environmental parameter controlling seasonal breeding in ewes is photoperiod. Short days stimulate, and long days inhibit breeding activity. One of the more intriguing enigmas of neuroendocrinology is the endocrine mechanism whereby a mere change in daylength initiates or prevents estrous cycles. Recent experiments have begun to solve this problem by demonstrating that in ewes, photoperiod governs response of the hypothalamopituitary axis to the negative feedback action of estradiol. In long days, estradiol is a potent inhibitor of gonadotropin secretion, whereas in short days it is relatively ineffective in this regard. These photoperiod-induced changes in estradiol feedback are proposed to permit or prevent estrous cycles by controlling the occurrence of a crucial step in the sequence of events leading to ovulation, namely a sustained, preovulatory rise in LH. Thus, estrous cycles cease in long days because an increase in estradiol negative feedback prevents the sustained rise in LH. In short days, estrous cycles resume because a decrease in estradiol feedback permits the sustained rise in LH required for ovulation. Even more puzzling, at present, than the mechanism of transduction of photoperiodic information into an endocrine event controlling seasonal breeding is the problem of transmission of photoperiodic information from the environment to the hypothalamo-pituitary axis. In sheep, early investigations of the transmission pathway have elicited provocative results, only some of which are similar to those obtained in other species. Among the questions which remain to be answered are: what is the location of the photoreceptors, and what, if any, are the roles of the suprachiasmatic nuclei and the pineal in photoperiodic control of seasonal breeding? These issues promise to provide a tantalizing challenge for future investigations into the photoneuroendocrine control of seasonal breeding.
\end{abstract}

During the course of evolution, nature selects against those animals whose young are born when conditions for survival are not optimal. As a result, for most wild species, breeding activity occurs at a specific time of year. Endocrinologists have only recently begun to investigate the neuroendocrine mechanisms whereby the environment interacts with the neuroendocrine-gonadal axis to regulate this remarkable process of reversible fertility. Among the first questions to be asked were (1) what is the major environmental parameter controlling seasonal breeding; (2) how is the environmental signal transduced into an endocrine event; and (3) by what pathway is the environmental signal transmitted to the hypothalamo-pituitary axis? This review will describe several experiments designed to answer these questions, focusing mainly on data obtained in female sheep.

\section{PHOTOPERIOD-THE MAJOR ENVIRONMENTAL REGULATOR OF SEASONAL BREEDING}

In answer to the first question, in sheep the major environmental parameter controlling seasonal breeding is photoperiod. This answer is not surprising since on a given day, photoperiod is constant from year to year, whereas other environmental parameters, such as temperature, are quite variable. One of the first reports of photoperiodic control of breeding seasons in sheep was made by Marshall (1937), who observed that breeding seasons were reversed in sheep transported to the southern hemisphere. Since then, a number of investigators have employed artificial photoperiods to examine photoperiodic control of seasonal breeding in more detail (Yeates, 1949; Hafez, 1952; Mauléon and Rougeot, 


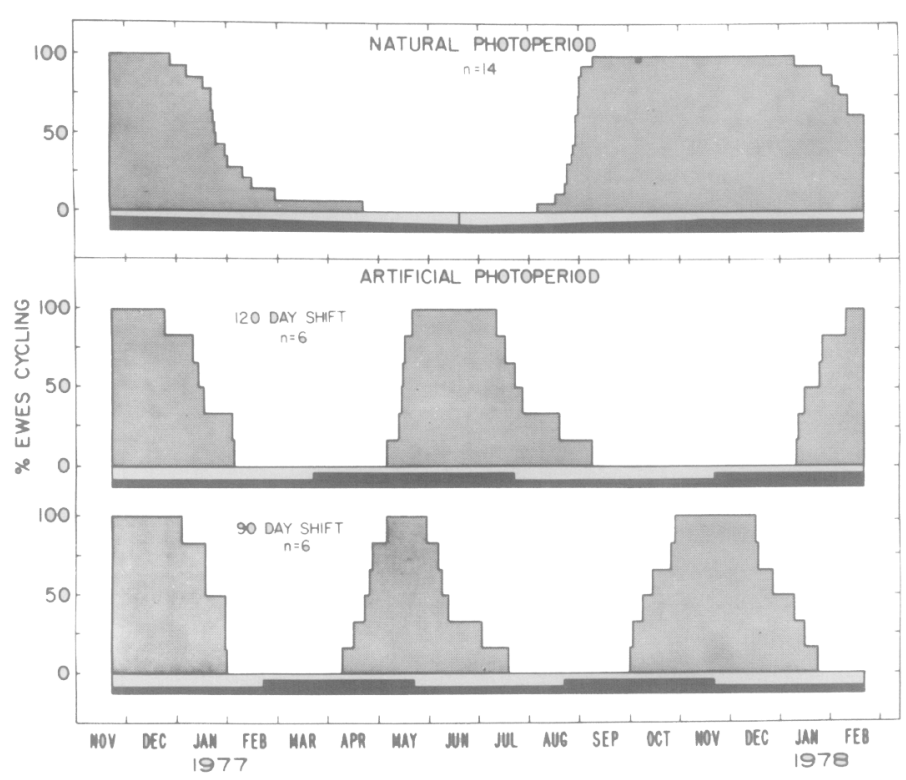

Fig. 1. Photoperiodic control of seasonal breeding, illustrated by comparison of occurrence of breeding seasons among ewes housed under natural photoperiodic conditions (upper panel) and artificial photoperiods consisting of 120 -day (middle panel) or 90 -day (lower panel) alternating long days (16L:8D) and short days (8L:16D). Photoperiod is indicated by horizontal bar below each panel, open and closed portions depicting hours of light and dark per day, respectively. Vertical line in natural photoperiod bar indicates summer solstice. Onset of anestrus in individual ewes defined as first missed ovulation; onset of breeding season defined as first ovulation based on serum progesterone concentrations.

1962; Thwaites, 1965; Ducker and Bowman, 1970; Ducker et al., 1970; Newton and Betts, 1972; Pelletier and Ortavant, 1975a; Lincoln et al., 1977; Legan and Karsch, 1980a). The results of one of these studies are illustrated in Fig. 1.

Occurrence of estrous cycles was monitored in two groups of ewes housed under the following artificial photoperiods: (1) abrupt shifts between short-day (8L:16D) and long-day (16L:8D) photoperiods every 90 days, and (2) abrupt shifts between the same artificial photoperiods every 120 days. In addition, occurrence of breeding and anestrous seasons were monitored in a third group of ewes maintained outdoors under natural photoperiodic conditions. In the latter group photoperiod gradually ranged between 9L:15D on the winter solstice and 15L:9D on the summer solstice.

In contrast to the biannual transitions between breeding seasons observed in ewes housed under natural photoperiod, the artificial photoperiods induced onset or cessation of estrous cycles every 90 days in one group and every 120 days in the other (Fig. 1). Thus, each exposure to long days caused a shift to ancstrus, whereas short days elicited onset of the breeding season, regardless of whether a given change in photoperiod occurred during the natural anestrous or breeding season. Further, at the end of one year, these two groups were $180^{\circ}$ out of phase, one group in "breeding season," the other in anestrus. Since temperature and other environmental parameters were not maintained constant in this study, but continued to fluctuate biannually, these results indicate that photoperiod is the major "Zeitgeber" for seasonal breeding in ewes. This conclusion receives further support from the observation that 
fluctuations in temperature alone cannot regulate breeding seasons when photoperiod is kept constant (WodzickaTomaszewska et al., 1967), however it is possible that temperature modulates the effects of the major "Zeitgeber," photoperiod (Dutt and Bush, 1955; Legan and Karsch, 1980a).

\section{TRANSDUCTION OF PHOTOPERIOD INTO AN ENDOCRINE EVENT}

Having established that photoperiod controls seasonal breeding, the next question is, how can a difference of a few hours of light per day bring about onset or cessation of estrous cycles? Although there is no complete answer to this question yet, significant progress toward that goal has been made in the past several years. Recent studies have focused on a single endocrine event which is not only controlled by photoperiod (Legan et al., 1977; Legan and Karsch, 1980a) but also is an essential condition for turning estrous cycles on or off (Hauger et al., 1977; Karsch et al., 1977; Legan and Karsch, 1979; Karsch et al., 1979; Goodman and Karsch, 1980; Karsch et al., 1980a), namely, a change in the negative feedback action of estradiol on LH secretion.

The first evidence indicating that such a change might be involved in control of seasonal breeding was the observation that transitions between breeding seasons are accompanied by changes in the negative feedback action of estradiol. This was demonstrated by measuring fluctuations in serum $\mathrm{LH}$ concentrations in a group of estradiol-treated ovariectomized ewes housed with intact ewes under natural photoperiod (Fig. 2). Onset of anestrus or breeding season in the intact ewes coincided with a marked decrease or increase, respectively, in serum $\mathrm{LH}$ levels in the estradiol-treated ovariectomized ewes. These dramatic fluctuations in $\mathrm{LH}$ could not be attributed to seasonal changes in metabolic clearance of estradiol since

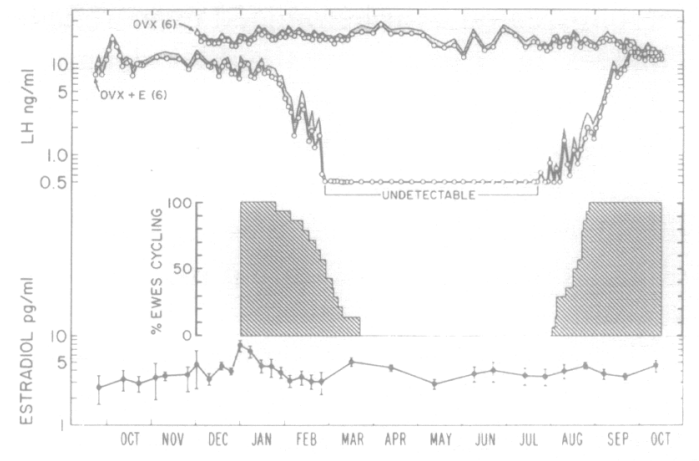

FIG. 2. Seasonal change in response to the negative-feedback action of estradiol on tonic LH secretion. The upper portion depicts serum LH levels (mean $+\mathrm{SE}$ ) in ovariectomized ewes treated with estradiol (OVX $+\mathrm{E}, n=6)$ or empty (OVX, $n=6) \mathrm{sc}$ Silastic implants. The lower portion depicts serum estradiol concentrations (mean $\pm \mathrm{SE}$ ) in the estradioltreated ewes. The histogram illustrates the time of onset of the breeding and anestrous seasons in a separate group of 14 intact ewes housed outdoors with the other ewes. Reproduced, with permission, from Karsch et al. (1980a).

serum estradiol concentrations in the ovariectomized ewes remained relatively constant throughout the year. Further, that the seasonal fluctuations in $\mathrm{LH}$ are not solely the result of a steroid-independent change in the LH release mechanism is indicated by the absence of seasonal differences in mean serum LH levels in a separate group of ovariectomized ewes treated with empty implants. This result, which is similar to that observed in red deer stags (Lincoln and Kay, 1979), but in contrast to that obtained in rams (Pelletier and Ortavant, 1975a) and numerous other species (Davis and Meyer, 1973; Turek et al., 1975, Garcia and Ginther, 1976; Mattocks et al., 1976), does not preclude the existence of small steroid-independent changes in the $\mathrm{LH}$ release mechanism. However in ewes, the importance of steroid-independent changes in $\mathrm{LH}$ in the regulation of seasonal breeding is overshadowed by those which are steroid dependent (Karsch et al., 1980a). Therefore the foregoing results demonstrate that seasonal variations in $\mathrm{LH}$ concentrations in 
steroid-treated ovariectomized ewes reflect changes in response of the hypothalamopituitary axis to the negative feedback action of estradiol such that estradiol exerts a potent negative feedback action on $\mathrm{LH}$ during anestrus, whereas it is relatively ineffective in this regard during the breeding season.

If such variations in response to estradiol negative feedback are an integral part of the mechanism mediating photoperiodic control of seasonal breeding in the ewe, they should accompany all photoperiod-induced transitions between breeding season and anestrus, whether in or out of phase with the natural breeding or anestrous seasons. To determine whether this is the case, a group of estradiol-treated ovariectomized ewes was housed with the intact ewes which were exposed to 90-day alternating long- and short-day photoperiods. Regard- less of the time of year, each exposure to an artificial short-day photoperiod was accompanied by a decrease in response to estradiol negative feedback in steroid-treated ovariectomized ewes (Fig. 3). Further, this change in response occurred simultaneously with onset of estrous cycles in intact ewes. Conversely, each exposure to long days caused an increase in response to estradiol coincident with onset of anestrus. Similar results were obtained from ewes maintained under 120-day alternations between long- and short-day photoperiods. Further, identical results were obtained when serum FSH levels were measured (Legan and Karsch, 1980a). Such photoperiod-induced changes in response to the feedback control of gonadal steroids have also been demonstrated in hamsters (Tamarkin et al., 1976; Turek, 1977) and in rams (Pelletier and Ortavant, 1975b). These results provide strong

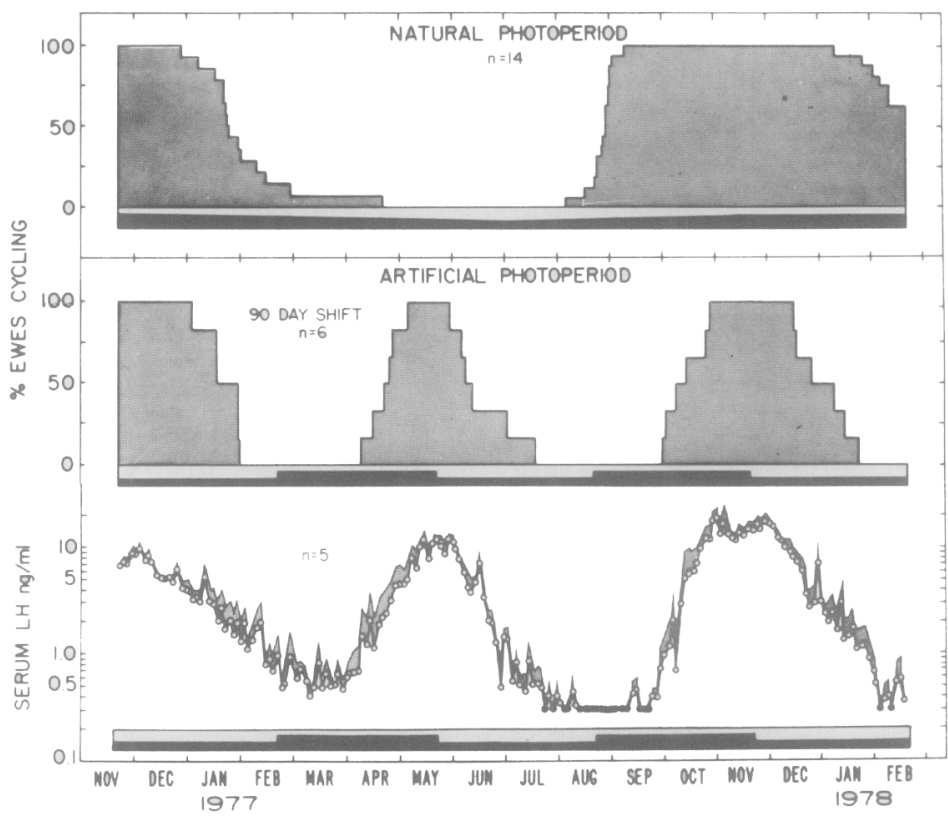

FIG. 3. Timing of breeding seasons in intact ewes and changes in tonic $\mathrm{LH}$ secretion in estradioltreated ovariectomized ewes. Upper panel: Occurrence of estrous cycles in 14 intact ewes exposed to natural environmental photoperiod. Middle panel: Occurrence of estrous cycles in 6 intact ewes housed under abrupt 90-day alternating long-day (16L:8D) and short-day (8L:16D) artificial photoperiods. Lower panel: Mean + SE serum LH concentrations in 5 estradiol-treated ovariectomized ewes subjected to the same regimen of artificial photoperiods. See legend to Fig. 1 for further details. Reproduced, with permission, from Legan and Karsch (1979). 
support for the hypothesis that changes in photoperiod cause seasonal breeding in some species by inducing changes in response to the negative feedback of gonadal steroids (Hoffmann, 1973; Pelletier and Ortavant, 1975b).

If this is the case, how could a photoperiod-induced change in steroid feedback prevent or initiate estrous cycles? The answer is in the form of a hypothesis which was proposed (Legan et al., 1977) to explain the photoperiodic control of seasonal breeding. According to this hypothesis, which has been tested experimentally (Karsch et al., 1979; Legan and Karsch, 1979; Goodman and Karsch, 1980; Goodman et al., 1980; Karsch et al., 1980a; Karsch et al., 1980b), occurrence of estrous cycles is dependent on a sequence of endocrine events. If one step in the sequence fails, estrous cycles are terminated resulting in anestrus. Within this framework, the key to seasonal breeding is that seasonal changes in response to estradiol determine whether the critical step, and thus the entire sequence, succeeds or fails.

The essentials of this hypothesis are summarized in Fig. 4. During the breeding season (Fig. 4, left panel), the end of an estrous cycle is marked by a decline in serum progesterone concentrations which accompanies regression of the corpus luteum. This releases the hypothalamopituitary axis from the negative feedback action of progesterone on tonic LH secretion, and serum LH increases (Baird and Scaramuzzi, 1976; Hauger et al., 1977; Karsch et al., 1977; Karsch et al., 1979; Karsch et al., 1980b). The rising tide of LH in turn stimulates a parallel increase in ovarian estradiol secretion (Baird et al., 1976; Baird, 1978; Karsch et al., 1979; Goodman and Karsch, 1980). These concomitant increases in $\mathrm{LH}$ and estradiol are maintained until the threshold for the preovulatory LH surge is reached (Goding et al., 1969), which leads to ovulation and formation of a new corpus luteum

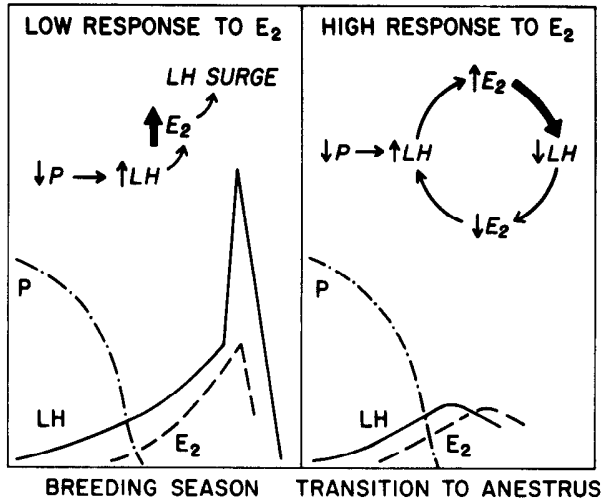

FIG. 4. Hypothesis for the endocrine basis of seasonal breeding in intact ewes. The left panel depicts the sequence of events leading to the preovulatory $\mathrm{LH}$ surge during the breeding season. The right panel illustrates that the LH surge does not occur during the transition to anestrus because of an increased response to the negative-feedback action of estradiol $\left(E_{2}\right)$. The symbol P represents progesterone. Reproduced, with permission, from Legan et al. (1977).

(Robertson, 1967). Thus a new cycle begins.

The hypothesis proposes that this cascade of events can occur only during the breeding season when response to estradiol negative feedback is low so that the critical step, a sustained parallel increase in LH and estradiol, can occur. In contrast, during anestrus, this crucial step is prevented by an increase in response to the inhibitory action of estradiol (Fig. 4, right panel). Thus, during the transition to anestrus when the last corpus luteum of the breeding season regresses, the decline in progesterone once again allows serum LH levels to increase and drive a concomitant rise in estradiol. Now, however, estradiol exerts a potent negative-feedback action on $\mathrm{LH}$ and prevents any further increase in LH. Consequently, there is no parallel, sustained increase in LH and estradiol, no signal is given for the LH surge, and anestrus begins. Serum progesterone, $\mathrm{LH}$, and estradiol concentrations remain low until there is a decrease in response to the negative feedback of estradiol and the sustained, parallel increases in LH and estradiol can 
occur. Then, an LH surge is triggered and the breeding season begins.

Although this hypothesis does not include a role for serum FSH, it is not because FSH is not important, but rather because the specific role of FSH in control of seasonal breeding in the ewe remains to be determined.

Based on the foregoing considerations, we have described how a photoperiodinduced change in response to the negative-feedback action of estradiol might initiate or prevent estrous cycles. Thus, short days cause a decrease in response to estradiol which leads to the breeding season, whereas long days bring about an increase in response to estradiol, which results in anestrus.

\section{TRANSMISSION PATHWAY FOR PHOTOPERIODIC INFORMATION}

Having established that changes in daylength are transduced into an increase or decrease in response of the hypothalamopituitary axis to steroid feedback, the next question is, how is photoperiodic information transmitted to the hypothalamopituitary axis? Based on evidence obtained in hamsters, the following pathway has been proposed (Fig. 5). Transmission of photic information mediating control of

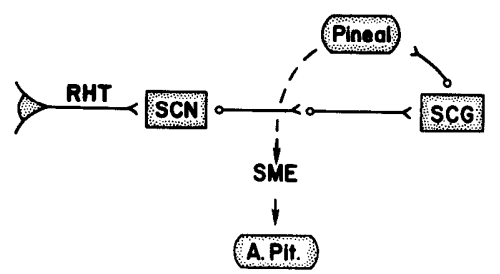

FIG. 5. Proposed pathway for transmission of photoperiodic information. Neural connections conduct the photic signals from the eye to the suprachiasmatic nucleus (SCN) via the retinohypothalamic tract (RHT), and thence to the pineal via the superior cervical ganglion (SCG). From the pineal, a humoral signal, represented by the broken arrow, transmits the signal to the hypothalamo-pituitary unit (SME and A. Pit.). seasonal breeding begins with the eyes, which contain the photoreceptors (Hoffman and Reiter, 1965; Reiter, 1968; Reiter, 1972). These receptors most likely transmit the information to the suprachiasmatic nucleus of the hypothalamus via a monosynaptic pathway known as the retinohypothalamic tract (Eichler and Moore, 1974; Rusak and Morin, 1976; Stetson and Watson-Whitmyre, 1976). Although specific neural tracts have not been identified beyond this point, the photoperiodic information is probably transmitted to the pineal gland by way of the superior cervical ganglia (Reiter and Hester, 1966; Reiter, 1972; Ariëns-Kappers, 1976). Since there are no known neural efferents from the pineal (Ariëns-Kappers, 1976), a humoral signal from this gland is presumed to transmit the information to the hypothalamo-pituitary unit (Turek and Campbell, 1979).

What is known about the transmission pathway for photoperiodic information in the sheep, and how does it compare with that in hamsters? Although early work indicated that the pineal is not essential for seasonal breeding in sheep (Roche et al., 1970), more recent studies indicate that the pineal is important in the photoperiodic responses mediating control of seasonal breeding. In one such experiment, the superior cervical ganglia were removed in rams housed under alternating long- and short-day artificial photoperiods (Lincoln, 1979) (Fig. 6). Since the superior cervical ganglia provide an important neural input to the pineal (Ariëns-Kappers, 1976), this operation is considered to be a functional pinealectomy. Photoperiodic entrainment of changes in testicular size were abolished following superior cervical ganglionectomy. The testes remained large for almost 2 years, regardless of photoperiod. This striking result prompted Lincoln to dub the ganglionectomized animal "the ram for all seasons." Although these results must be interpreted with caution because ganglionectomy not only denervates the pineal but also removes a large portion of autonomic 

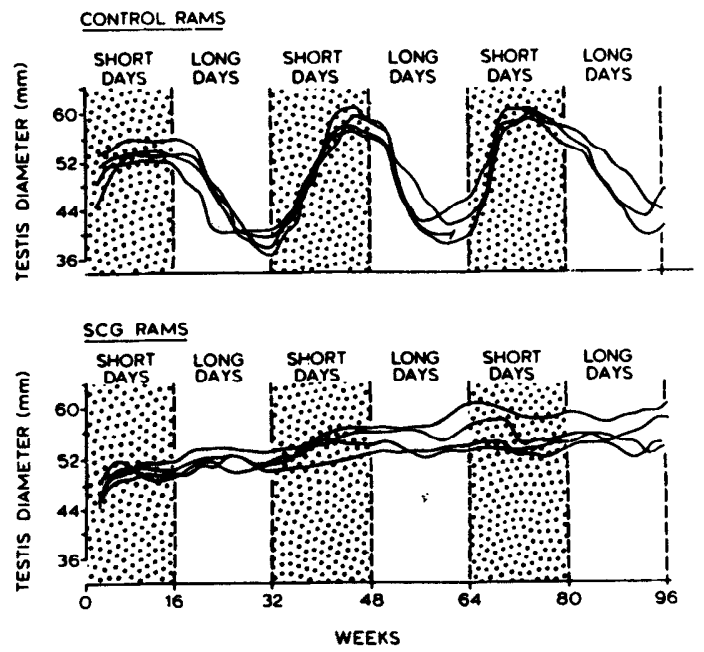

FIG. 6. Effect of superior cervical ganglionectomy on photoperiod-induced changes in testis size. Fluctuations in testicular diameter in four control Soay rams (upper panel) and four superior cervical ganglionectomized (SCG) Soay rams (lower panel) which were exposed to alternating 16-week periods of long days (16L:8D) and short days (8L:16D). Reproduced, with permission, from Lincoln and Short (1980).

innervation to the head, they are supported by the observation that pinealectomy abolishes photoperiodic control of estrous cyclicity and changes in response to estradiol in ewes (Bittman et al., 1981). Thus, both sheep and hamsters employ the superior cervical ganglia and pineal for transmission of photoperiodic information mediating seasonal breeding.

What about the rostral components of the pathway? The suprachiasmatic nucleus has been implicated in transmission of photoperiodic information for two reasons. The first is that it is an important component in generation of circadian rhythms (Moore and Eichler, 1972; Stephan and Zucker, 1972; Moore and Klein, 1974; Stetson and Watson-Whitmyre, 1976; Rusak, 1977). One of these, the rhythm in photosensitivity, is employed in measuring daylength in hamsters (Elliott et al., 1972; Stetson et al., 1975), birds (Follett and Sharpe, 1969; Turek, 1972), and probably in sheep (Garnier et al., 1977; Lincoln, 1978; Ortavant et al., 1978). Thus, it follows that lesions of the suprachiasmatic nucleus should impair an animal's ability to respond to changes in daylength. In hamsters, this is the case; such lesions prevent testicular regression induced by short days (Rusak and Morin, 1976). In sheep, some support for a role of the suprachiasmatic nucleus in control of seasonal breeding is provided by a recent report indicating that suprachiasmatic lesions prolong the breeding season (Domanski et al., 1980).

The second reason for implicating the suprachiasmatic nucleus in transmission of photic information is that it is the terminus of a monosynaptic pathway from the retina to the hypothalamus. The retinohypothalamic tract has been identified in a variety of species, including hamsters (Moore, 1973; Eichler and Moore, 1974). In addition, we have identified this tract in sheep by autoradiographic localization of $\left[{ }^{3} \mathrm{H}\right]$ proline $(250 \mu \mathrm{Ci}) 1$ week following its injection into the vitreous chamber of the eye. This technique is based on the assumption that radioactive amino acid is taken up by the retinal ganglion cells, incorporated into protein, and transported to the terminal by axoplasmic flow. The labeled proteins and thus the nerve terminals can be localized by fixing the tissue at an appropriate time after injection, and processing it for autoradiography. As can be seen in Fig. 7, following this procedure specific localization of radioactivity was most dense in the suprachiasmatic nucleus. Accumulation was next heaviest in the optic chiasm, whereas background or nonspecific accumulation of radioactivity, such as that seen in the third ventricle and the tissue dorsal and lateral to the suprachiasmatic nucleus, was observed throughout the remainder of the hypothalamus. These results indicate there is a direct neural pathway from the eyes to the suprachiasmatic nucleus in sheep, and suggest that photoperiodic information may be transmitted to the hypothalamus via this route.

It is important to note, however, that ex- 

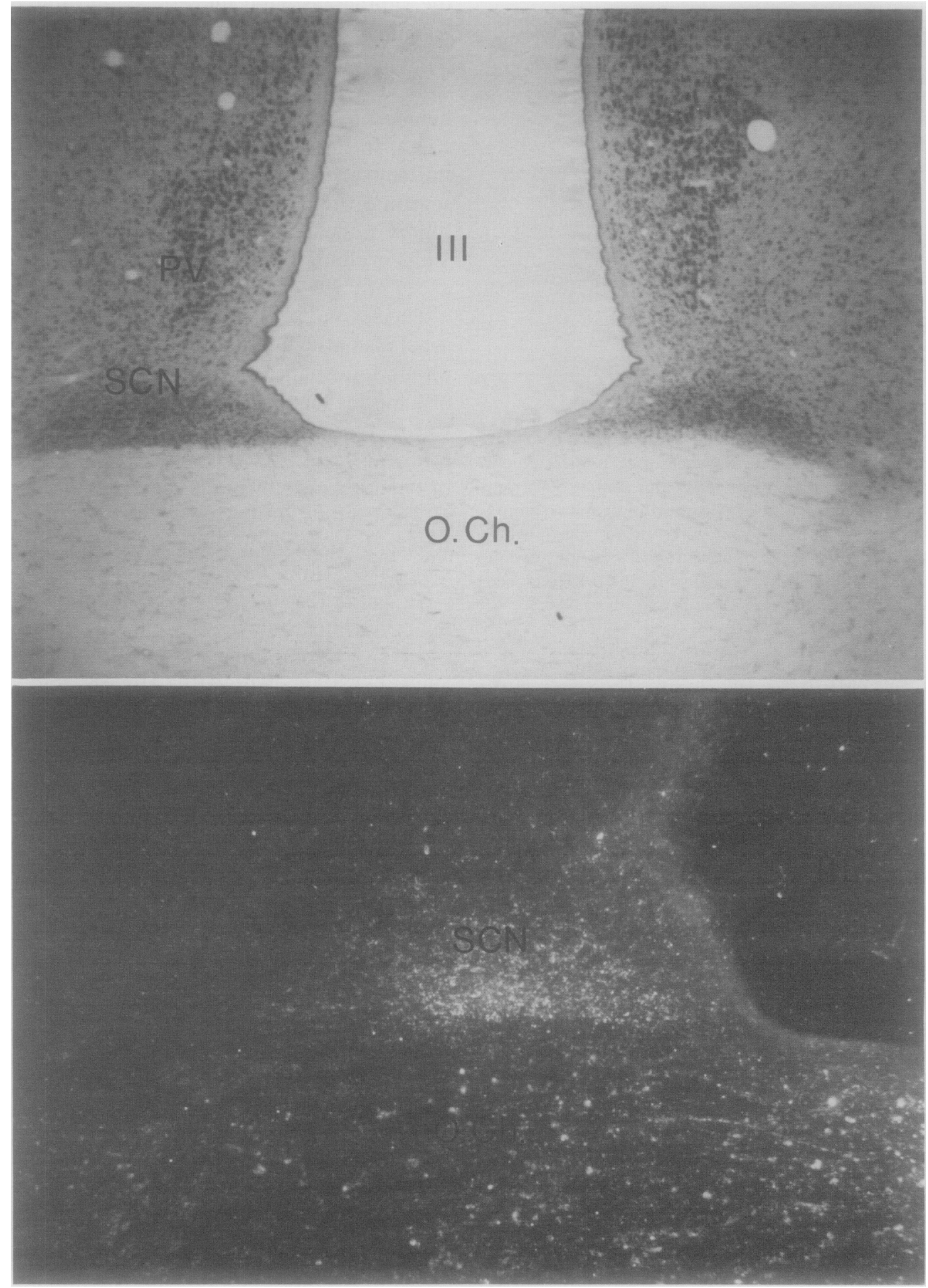
istence of a retinohypothalamic tract does not prove that the retina is the photoreceptor, or that this is the only path whereby photic signals are transmitted to the hypothalamus. In this regard, it is interesting that birds do not use their eyes for photoperiodic control of reproduction, but employ extraretinal photoreceptors (Benoit, 1964; Menaker and Keats, 1968). Is it possible that mammals also use extraretinal photoreception for photoperiodic control of reproduction? The site of the mammalian photoreceptor has only been examined in a few species. In ferrets (Herbert et al., 1978), hamsters (Reiter, 1968; Rusak and Morin, 1976), and gerbils (Dixit et al., 1977), photoperiodic control of reproduction is abolished following blinding. Therefore it is generally presumed that in mammals the retina is the site of the photoreceptor involved in control of seasonal breeding, although there is evidence for extra-retinal photoreception in neonatal rats (Zweig et al., 1966; Wetterberg et al., 1970). What is known about the photoreceptor in sheep?

Earlier observations indicated that seasonal reproductive function was maintained for $2 \frac{1}{2}$ years following blinding in ewes housed under natural environmental conditions (Clegg et al., 196\%). These results have three possible interpretations: (1) ewes have extraretinal photoreceptors; (2) the blind ewes were responding to other environmental cues, such as temperature, or other sighted sheep; or (3) there is an endogenous circannual rhythm of seasonal breeding in sheep. Therefore, in a recent attempt to reexamine whether the eyes are necessary for photoperiodic entrainment of breeding seasons, ewes blinded by bilateral enucleation were exposed to 90-day alternating long- and short-day artificial photo- periods. Surprisingly, following blinding, photoperiodic entrainment was maintained for more than a year (Legan and Karsch, $1980 \mathrm{~b})$. Since a sighted ram was present, a final conclusion cannot be drawn until it is determined whether blind ewes can be entrained by pheromonal signals from a sighted ram. However, the results obtained so far indicate first, that the eyes are not necessary for photoperiodic entrainment of breeding seasons in ewes and second, that blind ewes perceive changes in photoperiod by means of either extraretinal photoreceptors or pheromones, both of which are provocative possibilities.

\section{SUMMARY}

It has been demonstrated that photoperiod is the "Zeitgeber" for control of seasonal breeding in the ewe. Seasonal changes in photoperiod are transduced into biannual changes in response of the hypothalamo-pituitary axis to the negative feedback action of estradiol. These changes in response to steroid feedback play a pivotal role in onset or cessation of estrous cycles by means of their capacity to promote or prevent a sustained increase in circulating $\mathrm{LH}$. The sustained rise in $\mathrm{LH}$ is the critical step in a sequence of events leading to ovulation; whether it occurs or not determines whether breeding season or anestrus ensues, and depends on the response to estradiol. Thus, when estradiol feedback is low, sustained LH rises and the breeding season can occur; when response to estradiol is high, LH rises cannot occur and anestrus results. With regard to transmission of the photoperiodic signals which control seasonal breeding, the information is not as complete. Although the eyes are not required for photoperiodic en-

FIG. 7. Autoradiographic localization of the retinohypothalamic tract in the ewe. Upper panel: A bright field photomicrograph of a cresyl violet-stained frontal section of the ovine hypothalamus. Lower panel: Dark field photomicrograph of an adjacent section at higher power. The white dots are silver grains which represent localization of $\left[{ }^{3} \mathrm{H}\right]$ proline 1 week after injection into the anterior chamber of the eye. PV, paraventricular nucleus; SCN, suprachiasmatic nucleus; III, third ventricle; O. Ch., optic chiasm. 
trainment of seasonal breeding, it remains to be determined whether sighted ewes employ their eyes, or extraretinal photo- or olfactory receptors, or both for control of seasonal breeding. Finally, determining the roles, if any, of the retinohypothalamic tract, suprachiasmatic nucleus, superior cervical ganglia, and pineal in transmission of photoperiodic information will provide a stimulating challenge for further investigation of the photoneuroendocrine control of seasonal breeding.

\section{ACKNOWLEDGMENTS}

I wish to thank my colleagues, Drs. Fred J. Karsch, Douglas L. Foster, Robert L. Goodman, and Kathleen D. Ryan, who helped conceive and execute these studies. In addition, I am indebted to Mr. Douglas Doop for his invaluable assistance in designing and constructing the photoperiod-control rooms and in all aspects of the animal experimentation; Ms. Marjorie Hepburn and Ms. Barbara Glover, for their assistance in conducting the radioimmunoassays; Dr. Larry Kahn for his assistance with the autoradiography and the microphotography; and Drs. G. D. Niswender and Leo E. Reichert, Jr., for providing reagents used in the radioimmunoassays. This work was supported by grants from NIH (HD-08333 and HD-12450) and the Ford Foundation.

\section{REFERENCES}

Ariëns-Kappers, J. (1976). The mammalian pineal gland, a survey. Acta Neurochir. 34, 109-149.

Benoit, J. (1964). The role of the eye and of the hypothalamus in the photostimulation of gonads in the duck. Ann. N.Y. Acad. Sci. 117, 204-215.

Baird, D. T. (1978). Pulsatile secretion of LH and ovarian estradiol during the follicular phase of the sheep estrous cycle. Biol. Reprod. 18, 359-364.

Baird, D. T., and Scaramuzzi, R. J. (1976). Changes in the secretion of ovarian steroids and pituitary luteinizing hormone in the periovulatory period in the ewe: The effect of progesterone. J. Endocrinol. 70, 237-245.

Baird, D. T., Swanston, I., and Scaramuzzi, R. J. (1976). Pulsatile release of LH and secretion of ovarian steroids in sheep during the luteal phase of the estrous cycle. Endocrinology 98, 1490-1496.

Bittman, E. L., Karsch, F. J., and Hopkins, J. W. (1981). Role of the pineal gland in ovine photoperiodism: Regulation of negative feedback effects of estradiol upon LH. Biol. Reprod. 24, Suppl. 1, $104 \mathrm{~A}$.

Clegg, M. T., Cole, H. H., and Ganong, W. F. (1965).
The role of light in the regulation of cyclical estrous activity in sheep. Misc. Publ. U.S. Dept. 1005, 96-114.

Davis, G. J., and Meyer, R. K. (1973). Seasonal variation of LH and FSH in bilaterally castrated snowshoe hares. Gen. Comp. Endocrinol. 20, 61-68.

Dixit, V. P., Sharma, D. P., and Agrawal, M. (1977). The effects of light deprivation/blindness on testicular function of Gerbil (Meiones Hurrianae Jerdon). Endokrinologie 70, 13-18.

Domanski, E., Przekop, F., and Polkowska, J. (1980). Hypothalamic centres involved in the control of gonadotropin secretion. J. Reprod. Fert. 58, 493-499.

Ducker, M. J., and Bowman, J. C. (1970). Photoperiodism in the ewe. 3 . The effects of various patterns of increasing daylength on the onset of anoestrus in Clun Forest ewes. Anim. Prod. 12, 465-471.

Ducker, M. J., Thwaites, C. J., and Bowman, J. C. (1970). Photoperiodism in the ewe. 2. The effects of various patterns of decreasing daylength on the onset of oestrus in Clun Forest ewes. Anim. Prod. $12,115-123$.

Dutt, R. H., and Bush, L. F. (1955). The effect of low environmental temperature on initiation of the breeding season and fertility in sheep. J. Anim. Sci. 14, 885-896.

Eichler, V. B., and Moore, R. Y. (1974). The primary and accessory optic systems in the golden hamster, Mesocricetus auratus. Acta Anat. 89, 359-371.

Elliott, J. A., Stetson, M. H., and Menaker, M. (1972). Regulation of testis function in golden hamsters: A circadian clock measures photoperiodic time. Science 178, 771-773.

Follett, B. K., and Sharp, P. J. (1969). Circadian rhythmicity in photoperiodically induced gonadotropin release and gonadal growth in the quail. Nature (London) 223, 968-971.

Garcia, M. C., and Ginther, O. J. (1976). Effects of ovariectomy and season on plasma luteinizing hormone in mares. Endocrinology 97, 958-962.

Garnier, D. H., Ortavant, R., Mansard, F. X., and Terqui, M. (1977). Influence de la lumiére sur les variations de la testostéronémie chez le bélier: mise en évidence d'une phase photosensible au cours du rhythme diurne. C.R.H. Seances Acad. Sci. 284, 61-64.

Goding, J. R., Catt, K. J., Brown, J. M., Kaltenbach, C. C., Cumming, I. A., and Mole, B. J. (1969). Radioimmunoassay for ovine luteinizing hormone. Secretion of luteinizing hormone during estrus and following estrogen administration in the sheep. Endocrinology 85, 133-142.

Goodman, R. L., and Karsch, F. J. (1980). Control of seasonal breeding in the ewe: Importance of changes in response to sex-steroid feedback. In 
"'Progress in Reproductive Biology"' (R. J. Reiter and B. K. Follett, eds.), Vol. 5, pp. 134-154. S. Karger, Basel.

Goodman, R. L., Legan, S. J., Ryan, K. D., Foster, D. L., and Karsch, F. J. (1980). Two effects of estradiol that normally contribute to the control of tonic LH secretion in the ewe. Biol. Reprod. 23 , 415-422.

Hafez, E. S. E. (1952). Studies on the breeding season and reproduction of the ewe. J. Agr. Sci. 42, 189-265.

Hauger, R. L., Karsch, F. J., and Foster, D. L. (1977). A new concept for control of the estrous cycle of the ewe based on the temporal relationships between luteinizing hormone, estradiol and progesterone in peripheral serum and evidence that progesterone inhibits tonic LH secretion. $E n$ docrinology 101, 807-817.

Herbert, J., Stacey, P. M., and Thorpe, D. H. (1978). Recurrent breeding seasons in pinealectomized or optic-nerve-sectioned ferrets. J. Endocrinol. 78, 389-397.

Hoffman, R. A., and Reiter, R. J. (1965). Pineal gland: Influence on gonads of male hamsters. Science 148, 1609-1611.

Hoffmann, J. C. (1973). Light and feedback control of gonadotropin secretion. In "Proceedings of the IVth International Congress of Endocrinology, Washington, D.C., June 18-24, 1972' (R. O. Scow, ed.), Int. Congr. Ser. Excerpta Med. 273, pp. 886-890. Elsevier, New York.

Karsch, F. J., Foster, D. L., Legan, S. J., Ryan, K. D., and Peter, G. K. (1979). Control of the preovulatory endocrine events in the ewe: Interrelationship of estradiol, progesterone, and luteinizing hormone. Endocrinology 105, 421-426.

Karsch, F. J., Goodman, R. L., and Legan, S. J. (1980a). Feedback basis of seasonal breeding: Test of an hypothesis. J. Reprod. Fert. 58, $521-535$.

Karsch, F. J., Legan, S. J., Hauger, R. L., and Foster, D. L. (1977). Negative feedback action of progesterone on tonic luteinizing hormone secretion in the ewe: Dependence on the ovaries. Endocrinology 101, 800-806.

Karsch, F. J., Legan, S. J., Ryan, K. D., and Foster, D. L. (1980b). Importance of estradiol and progesterone in regulating $\mathrm{LH}$ secretion and estrous behavior during the sheep estrous cycle. Biol. Reprod. 23, 404-413.

Legan, S. J., and Karsch, F. J. (1979). Neuroendocrine regulation of the estrous cycle and seasonal breeding in the ewe. Biol. Reprod. 20, 74-85.

Legan, S. J., and Karsch, F. J. (1980a). Photoperiodic control of seasonal breeding in ewes: Modulation of the negative feedback action of estradiol. Biol. Reprod. 23, 1061-1068.
Legan, S. J., and Karsch, F. J. (1980b). Photoperiodic control of breeding seasons in blind ewes: Evidence for extra-retinal photoreceptors. Biol. Reprod. 22, (Suppl. 1), 34A.

Legan, S. J., Karsch, F. J., and Foster, D. L. (1977). The endocrine control of seasonal reproductive function in the ewe: A marked change in response to the negative feedback action of estradiol on luteinizing hormone secretion. Endocrinology 101, 818-824.

Lincoln, G. A. (1978). Induction of testicular growth and sexual activity in rams by a "skeleton" short-day photoperiod. J. Reprod. Fert. 52, 179-181.

Lincoln, G. A. (1979). Photoperiodic control of seasonal breeding in the ram: Participation of the cranial sympathetic nervous system. J. Endocrinol. 82, 135-147.

Lincoln, G. A., and Kay, R. N. B. (1979). Effects of season on the secretion of LH and testosterone in intact and castrated red deer stags (Cervus elaphus). J. Reprod. Fert. 55, 75-80.

Lincoln, G. A., Peet, M. J., and Cunningham, R. A. (1977). Seasonal and circadian changes in the episodic release of follicle-stimulating hormone, luteinizing hormone and testosterone in rams exposed to artificial photoperiods. J. Endocrinol. 72, 337-349.

Lincoln, G. A., and Short, R. V. (1980). Seasonal breeding: Nature's contraceptive. Recent Progr. Horm. Res. 36, 1-52.

Marshall, F. H. A. (1937). On change over in oestrous cycle in animals after transference across equator, with further observations on incidence of breeding season and factors controlling sexual periodicity. Proc. Roy. Soc. London. Ser. B 122, 413-428.

Mattocks, P. W., Jr., Farner, D. S., and Follett, B. K. (1976). The annual cycle in luteinizing hormone in the plasma of intact and castrated white-crowned sparrows, Zonotrichia leucophrys gambelli. Gen. Comp. Endocrinol. 30, 156-161.

Mauléon, P., and Rougeot, J. (1962). Régulation des saisons sexuelles chez des brebis de races différentes au moyen de divers rhythmes lumineux. Ann. Biol. Anim. Biochim. Biophys. 2, 209-222.

Menaker, M., and Keats, H. (1968). Extraretinal light perception in the sparrow. II. Photoperiodic stimulation of testis growth. Proc. Nat. Acad. Sci. USA 60, 146-151.

Moore, R. Y. (1973). Retinohypothalamic projection in mammals: A comparative study. Brain Res. 49, $403-409$.

Moore, R. Y., and Eichler, V. B. (1972). Loss of a circadian adrenal corticosterone rhythm following suprachiasmatic lesions in the rat. Brain Res. 42, 201-206.

Moore, R. Y., and Klein, D. C. (1974). Visual pathways and the central neural control of a circadian 
rhythm in pineal serotonin- $\mathrm{N}$-acetyltransferase activity. Brain Res. 71, 17-33.

Newton, J. E., and Betts, J. E. (1972). A comparison between the effects of various photoperiods on the reproductive performance of Scottish Halfbred ewes. I. Agr. Sci. 78, 425-433.

Ortavant, R., Pelletier, J., Ravault, J. P., and Thimonier, J. (1978). Annual cyclic variations in prolactin in sheep. In "Environmental Endocrinology" (I. Assenmacher and D. S. Farner, eds.), pp. 75-78. Springer-Verlag, New York.

Pelletier, J., and Ortavant, R. (1975a). Photoperiodic control of LH release in the ram. I. Influence of increasing and decreasing light photoperiods. Acta Endocrinol (Copenhagen) 78, 435-441.

Pelletier, J., and Ortavant, R. (1975b). Photoperiodic control of LH release in the ram. II. Light-androgens interaction. Acta Endocrinol. (Copenhagen) 78, $442-450$.

Reiter, R. J. (1968). Changes in the reproductive organs of cold-exposed and light-deprived female hamsters (Mesocricetus auratus). J. Reprod. Fert. 16, 217-222.

Reiter, R. J. (1972). Surgical procedures involving the pineal gland which prevent gonadal degeneration in adult male hamsters. Ann. Endocrinol. 33, 571-581.

Reiter, R. J., and Hester, R. J. (1966). Interrelationships of the pineal gland, the superior cervical ganglia and the photoperiod in the regulation of the endocrine systems of hamsters. Endocrinology 79, 1168-1170.

Robertson, H. A. (1967). Gonadotropin secretion in relation to oestrus and to ovulation. In "Reproduction in the Female Mammal" (G. E. Lamming and E. C. Amoroso, eds.), pp. 195-211. Plenum, New York/Butterworths, London.

Roche, J. F., Karsch, F. J., Foster, D. L., Takagi, S., and Dziuk, P. J. (1970). Effect of pinealectomy on estrus, ovulation and luteinizing hormone in ewes. Biol. Reprod. 2, 251-254.

Rusak, B. (1977). The role of the suprachiasmatic nuclei in the generation of circadian rhythms in the golden hamster, Mesocricetus auratus. J. Comp. Physiol. 118, 145-164.

Rusak, B., and Morin, L. P. (1976). Testicular responses to photoperiod are blocked by lesions of the suprachiasmatic nuclei in golden hamsters. Biol. Reprod. 15, 366-374.

Stephan, F. K., and Zucker, I. (1972). Circadian rhythms in drinking behavior and locomotor activity of rats are eliminated by hypothalamic lesions. Proc. Nat. Acad. Sci. USA 69, 1583-1586.

Stetson, M. H., Elliott, J. A., and Menaker, M. (1975). Photoperiod regulation of hamster testes: Circadian sensitivity to the effects of light. Biol. Reprod. 13, 329-339.

Stetson, M. H., and Watson-Whitmyre M. (1976). Nucleus suprachiasmaticus: The biological clock in the hamster? Science 191, 197-199.

Tamarkin, L., Hutchison, J. S., and Goldman, B. D. (1976). Regulation of serum gonadotropins by photoperiod and testicular hormone in the Syrian hamster. Endocrinology 99, 1528-1533.

Thwaites, C. J. (1965). Photoperiodic control of breeding activity in the Southdown ewe with particular reference to the effects of an equatorial light regime. J. Agr. Sci. 65, 57-64.

Turek, F. W. (1972). Circadian involvement in termination of the refractory period in two sparrows. Science 178, 1112-1113.

Turek, F. W. (1977). The interaction of photoperiod and testosterone in regulating serum gonadotropin levels in castrated male hamsters. Endocrinology 101, 1210-1215.

Turek, F. W., and Campbell, C. S. (1979). Photoperiodic regulation of neuroendocrine-gonadal activity. Biol. Reprod. 20, 32-50.

Turek, F. W., Elliott, J. A., Alvis, J. A., and Menaker, M. (1975). The interaction of castration and photoperiod in the regulation of hypophyseal and serum gonadotropin levels in male golden hamsters. Endocrinology 96, 854-860.

Wetterberg, L., Geller, E., and Yuwiler, A. (1970). Harderian gland: An extraretinal photoreceptor influencing the pineal gland in neonatal rats? $\mathrm{Sci}$ ence $167,884-885$.

Wodzicka-Tomaszewska, M., Hutchinson, J. C. D., and Bennett, J. W. (1967). Control of the annual rhythm of breeding in ewes: Effect of an equatorial daylength with reversed thermal seasons. $J$. Agr. Sci. 68, 61-67.

Yeates, N. T. M. (1949). The breeding season of the sheep with particular reference to its modification by artificial means using light. J. Agr. Sci. 39, $1-43$.

Zweig, M., Snyder, S. H., and Axelrod, J. (1966). Evidence for a nonretinal pathway of light to the pincal gland of newborn rats. Proc. Nat. Acad. Sci. USA 56, 515-520. 